Case Report

\title{
Advanced Hepatocellular Carcinoma with Subtotal Occlusion of the Inferior Vena Cava and a Right Atrial Mass
}

\author{
Christian Steinberg, ${ }^{1}$ Suzanne Boudreau, ${ }^{2}$ Felix Leveille, ${ }^{3}$ Marc Lamothe, ${ }^{4}$ \\ Patrick Chagnon, ${ }^{4}$ and Isabelle Boulais ${ }^{4}$ \\ ${ }^{1}$ Department of Cardiology, Quebec Heart and Lung Institute, Laval University, 2725 Chemin Sainte-Foy, \\ Quebec, QC, Canada G1V 4G5 \\ ${ }^{2}$ Department of Pathology, Hôtel-Dieu d'Arthabaska, 5 rue des Hospitalières Victoriaville, QC, Canada G6P 6N2 \\ ${ }^{3}$ Department of Nuclear Medicine, Hôtel-Dieu d'Arthabaska, 5 rue des Hospitalières Victoriaville, QC, Canada G6P 6N2 \\ ${ }^{4}$ Department of Internal Medicine, Hôtel-Dieu d'Arthabaska, 5 rue des Hospitalières Victoriaville, QC, Canada G6P 6N2
}

Correspondence should be addressed to Christian Steinberg; christian.steinberg.1@ulaval.ca

Received 19 February 2013; Accepted 14 March 2013

Academic Editors: B. S. Brooke, N. Espinola-Zavaleta, and M. Sindel

Copyright (C) 2013 Christian Steinberg et al. This is an open access article distributed under the Creative Commons Attribution License, which permits unrestricted use, distribution, and reproduction in any medium, provided the original work is properly cited.

\begin{abstract}
Hepatocellular carcinoma usually metastasizes to regional lymph nodes, lung, and bones but can rarely invade the inferior vena cava with intravascular extension to the right atrium. We present the case of a 75-year-old man who was admitted for generalized oedema and was found to have advanced HCC with invasion of the inferior vena cava and endovascular extension to the right atrium. In contrast to the great majority of hepatocellular carcinoma, which usually develops on the basis of liver cirrhosis due to identifiable risk factors, none of those factors were present in our patient.
\end{abstract}

\section{Introduction}

Primary hepatocellular carcinoma (HCC) is a quite uncommon tumor in North America and Western Europe but is the fifth most common cancer worldwide and the third leading cause of cancer-related death $[1,2]$. Most cases of HCC occur in patients with chronic liver disease or preexisting liver cirrhosis. Common causes for liver cirrhosis are chronic alcoholic liver disease or chronic viral hepatitis due to hepatitis $B$ virus or hepatitis $C$ virus infection [2]. Other risk factors for the development of HCC are metabolic diseases like hemochromatosis or alphal-antitrypsin deficiency, autoimmune liver diseases (autoimmune hepatitis, primary biliary cirrhosis), and aflatoxin exposition $[1,3-5]$. The incidence of HCC shows striking variations between different geographic regions and among different racial and ethnic background within the same country, suggesting a crucial role of genetic and environmental factors in the pathogenesis of HCC $[6,7]$. HCC is an aggressive tumor and can show extensive metastazation. It usually metastasizes to regional lymph nodes, lung, or bone but sometimes shows invasion of major blood vessels with endovascular extension $[8,9]$. In this report, we present the rare case of an advanced hepatocellular carcinoma with invasion of the inferior vena cava and intravascular extension to the right atrium in a patient without any preexisting liver disease.

\section{Case Report}

A 75-year-old Caucasian man presented to the emergency room of our hospital for dyspnea and new onset generalized oedema rapidly progressing over one week. The patient was known for stable coronary artery disease, paroxysmal atrial fibrillation with oral anticoagulation, chronic obstructive bronchitis, hypertension, and dyslipidemia. He had stopped smoking 3 years before, had no history of alcoholism, and had never taken illegal drugs.

Vital signs at presentation were stable. The patient was afebrile and not in respiratory distress. Physical examination revealed generalized oedema associated with ascites and hepatomegaly. The jugular veins were not distended, but 


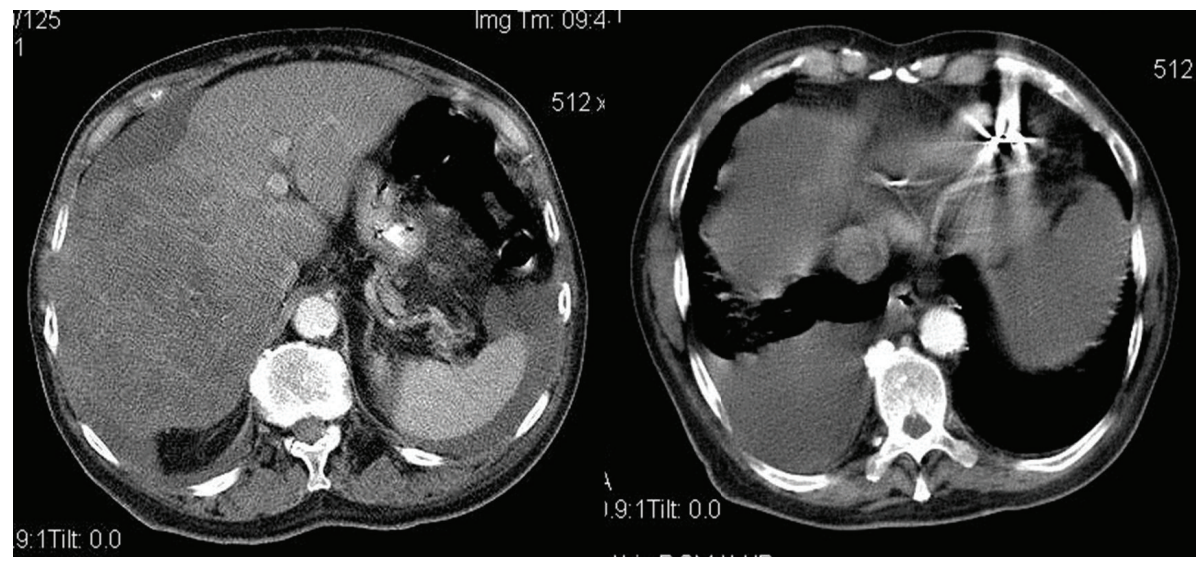

(a)

(b)

FIGURE 1: Contrast enhanced CT scan of thorax, abdomen, and pelvis.

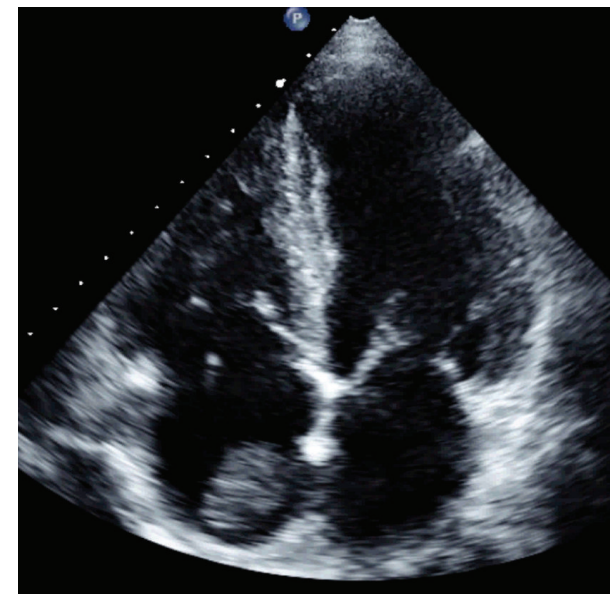

(a)

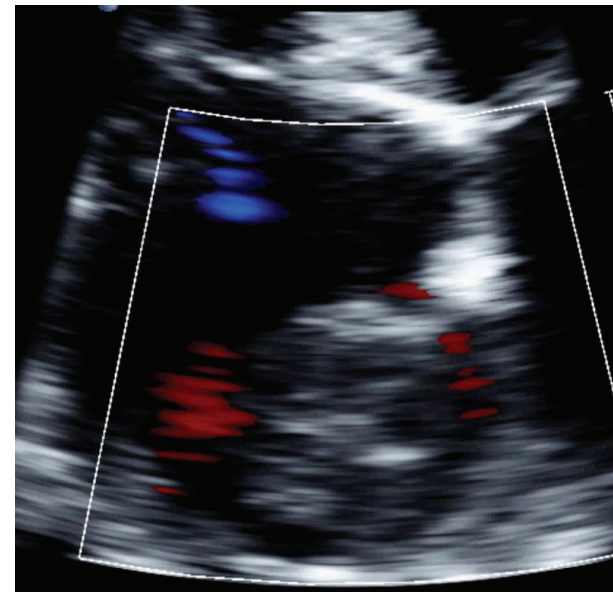

(b)

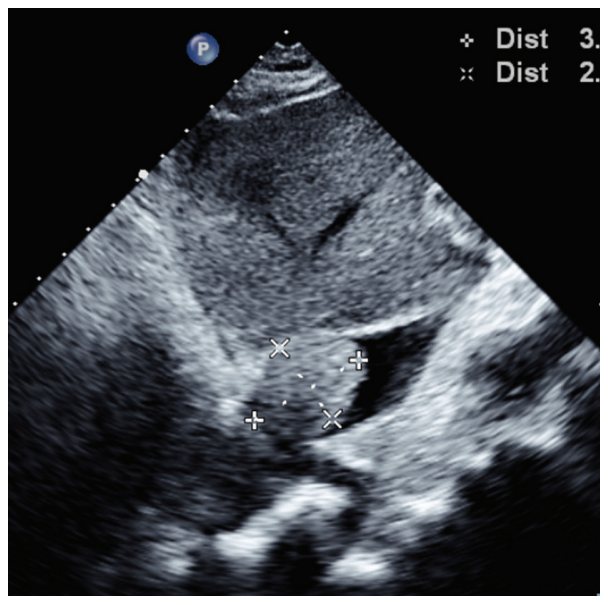

(c)

FIGURE 2: Transthoracic echocardiography. 


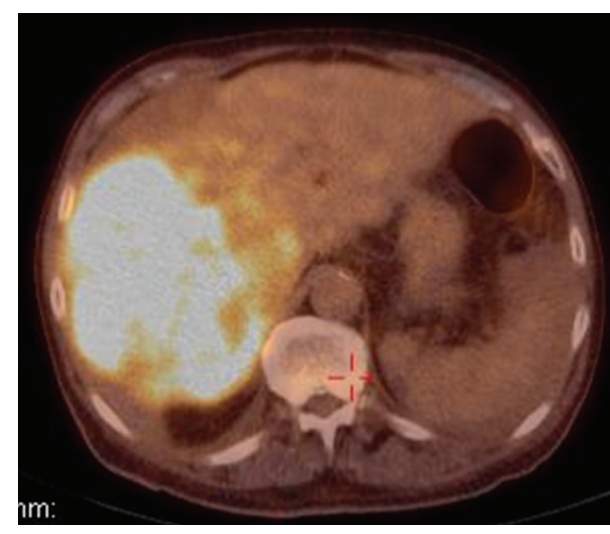

(a)

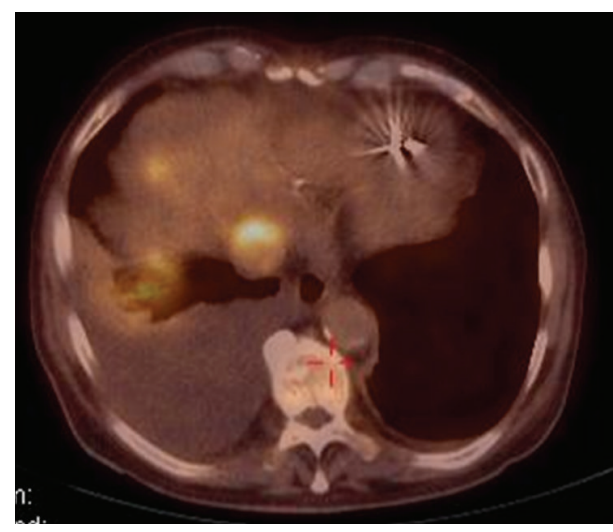

(b)

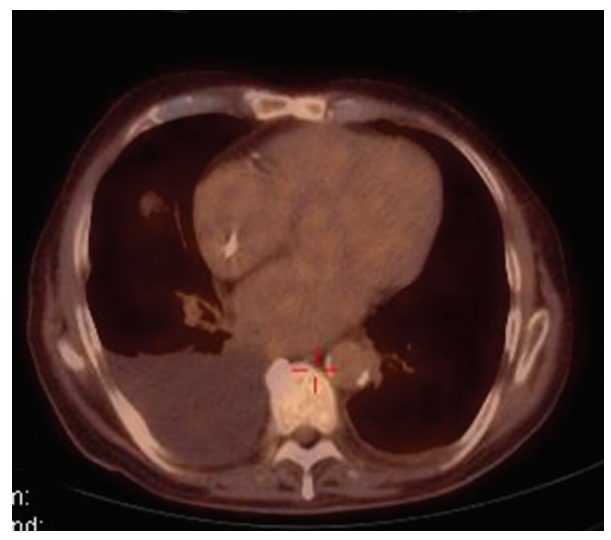

(c)

FIgure 3: Positron emission tomography-CT.

TABLE 1: Laboratory results on admission.

\begin{tabular}{lc}
\hline Red blood cells & $6.2 \times 10^{12} / \mathrm{L}$ \\
Hemoglobin & $160 \mathrm{~g} / \mathrm{L}$ \\
Hematocrit & 0.50 \\
INR & 5.10 \\
AST & $21 \mathrm{U} / \mathrm{L}$ \\
ALT & $91 \mathrm{U} / \mathrm{L}$ \\
Bilirubin (total) & $20 \mu \mathrm{mol} / \mathrm{L}$ \\
Alkaline phosphatase & $164 \mathrm{U} / \mathrm{L}$ \\
Albumin & $30 \mathrm{~g} / \mathrm{L}$ \\
\hline
\end{tabular}

there was a strong clinical suspicion of a right-sided pleural effusion. An initial chest X-ray confirmed an important right pleural effusion and a $1 \mathrm{~cm}$ sized nodule in the right lower lobe (not shown). Results of laboratory tests are shown in Table 1. Most strikingly, there was a new onset perturbation of liver markers.

A contrast enhanced CT scan of the chest, abdomen, and the pelvis was performed. The abdominal CT scan showed a very heterogeneous liver. Except for segments 2 and 3 , the whole liver contained multiple ill-defined and partially confluent hypodensities of different size suggesting an advanced neoplastic process (Figure 1(a)). There was also a doubt of a hypodense lesion inside the inferior vena cava (Figure 1(b)). The hepatic lesions were associated with a moderate quantity of ascites but no splenomegaly (Figure 1(a). The chest study confirmed the presence of a large right-sided pleural effusion and a $1 \mathrm{~cm}$ sized nodule in the anterior part of the right lower lung lobe (not shown). On transthoracic echocardiography, a well-defined, immobile oval mass with a smooth surface and a size of $23 \mathrm{~mm} \times 30 \mathrm{~mm}$ was noted in the right atrium (Figure 2(a)). The mass was not adherent to the interatrial septum (Figure 2(b)). The mass extended to the inferior vena cava where it reached a size of $34 \mathrm{~mm} \times$ $25 \mathrm{~mm}$, creating a subtotal occlusion with a pressure gradient of $13 \mathrm{mmHg}$ between the inferior vena cava and the right atrium (Figure 2(c)). The occluded inferior vena cava showed no respiratory compliance and had a diameter of $21 \mathrm{~mm}$.

A complete colonoscopy was negative for a neoplastic lesion, so liver biopsy under CT guidance was performed to establish a histological diagnosis. To complete the tumor staging and further characterize the endovascular lesion of the inferior vena cava and right atrium, a positron emission tomography-CT (PET-CT) was performed. On the PET imagery, there was a strong hypermetabolic zone in the right liver lobe covering an area of $13 \mathrm{~cm} \times 14 \mathrm{~cm} \times 13 \mathrm{~cm}$ (maximal 


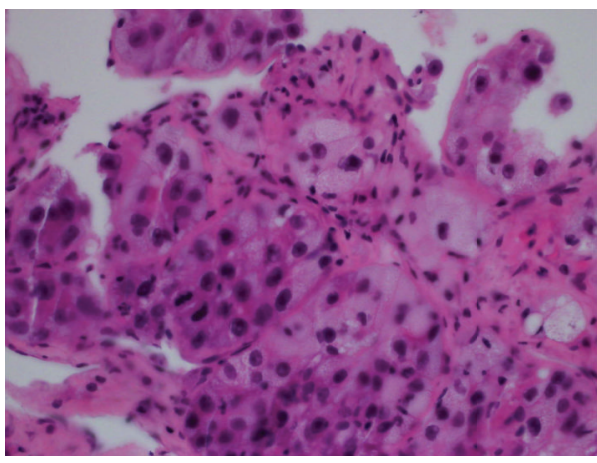

(a)

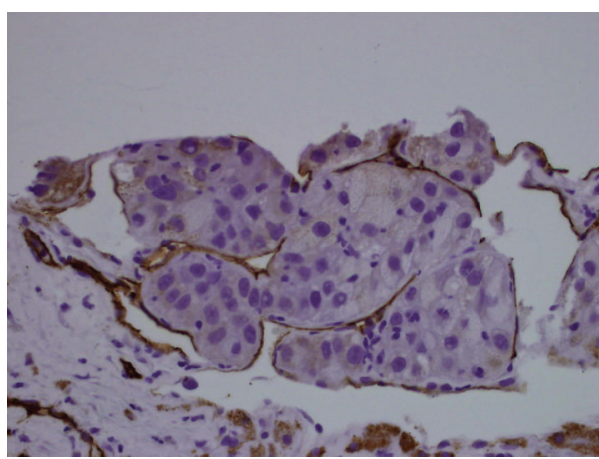

(c)

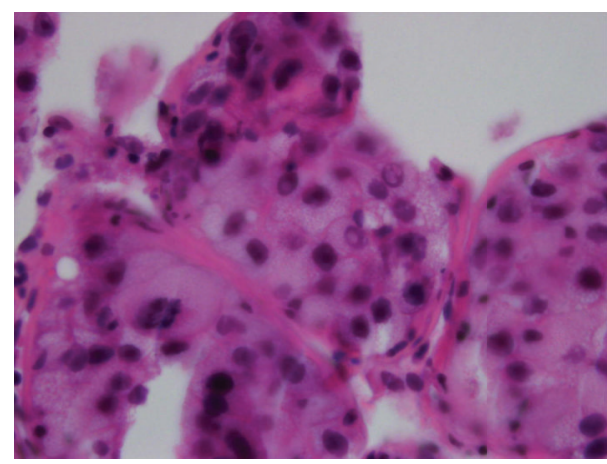

(b)

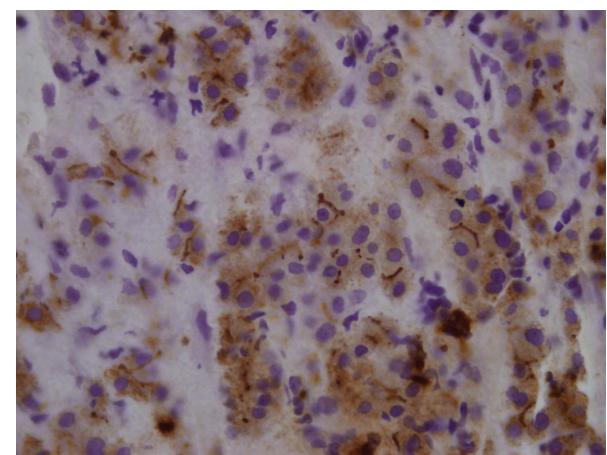

(d)

FIGURE 4: Liver biopsy. Hematoxylin and eosin staining (a) and (b). Immunostaining for CD34 (c) and for carcinoembryonic antigen (CEA) (d).

normalized capture index 8.9) (Figure 3(a)). This hypermetabolic zone corresponded to the hepatic lesions seen on the CT scan and extended inside the inferior vena cava over a distance of $3.5 \mathrm{~cm}$ (Figure 3(b)). The hypermetabolic zone stopped at the junction of the inferior vena cava with the right atrium. No abnormal hypermetabolism was noted inside the heart (Figure 3(c)). The lung nodule seen on the CT scan was also hypermetabolic with a capture index of 2.3 suggesting a metastasis (not shown).

The histological examination of the liver biopsy demonstrated a hepatocellular carcinoma with a well- and a poorlydifferentiated component (Figure 4). There were no microscopical signs of liver cirrhosis on the specimen. The serum level of alpha-fetoprotein was $270000 \mathrm{ng} / \mathrm{mL}$. Taken together, these results established the final diagnosis of a stage IV locally advanced hepatocellular carcinoma with endovascular extension and a single pulmonary metastasis. It remains unclear if the metabolic inactive part of the endocaval and intra-atrial mass represented a superimposed thrombosis or necrotic tumor tissue.

Laboratory tests to screen underlying risk factors of HCC were performed. Virus serology for hepatitis B, hepatitis C, and human immunodeficiency virus was negative. The serum ferritin level was $398 \mu \mathrm{g} / \mathrm{L}$, and the serum iron saturation was at $12 \%$. The electrophoresis of serum proteins was normal eliminating alphal-antitrypsin deficiency.

Confronted with the diagnosis, the patient did not desire further treatment and was orientated to palliative care.

\section{Discussion}

Although HCC usually metastasizes to regional lymph nodes, lung, or bones, primary liver cancer has also the propensity to invade major local blood vessels with intravascular extension $[8,9]$. Based on autopsy series, invasion of the inferior vena cava has been described in up to $9 \%-26 \%$ and intravascular extension to the right atrium in $2.4 \%-6.3 \%$ of cases of HCC [10-12]. Virtually all reported cases of HCC with intracaval invasion had preexisting liver cirrhosis and/or at least one classical risk factor for $\operatorname{HCC}[8,9,11]$. Our patient differs from the known literature in that he had neither any classical risk factors for HCC nor histological signs of underlying cryptogenic cirrhosis.

Patients with tumor invasion of the inferior vena cava and/or intravascular extension to the heart have a very poor outcome. Typical complications of intravascular tumor extension lead to secondary Budd-Chiari syndrome, right heart insufficiency, or massive pulmonary embolism secondary to detached tumor tissue or superimposed thrombotic material [13]. Local surgical and nonsurgical approaches as well as systemic therapy with antiangiogenic agents have been described for HCC patients with caval invasion. Very few patients are candidates for local surgery because of the high perioperative morbidity and mortality of those high-risk interventions, and clinical experience is limited to occasional cases or small series $[14,15]$. Nonsurgical local treatments like transarterial chemoembolization or local radiotherapy 
are only moderately effective and are also associated with important morbidity $[16,17]$. While HCC is little responsive to classical cytotoxic chemotherapy, the focus of systemic therapy has shifted to immunomodulatory molecules [18]. Among them, Sorafenib, an oral multikinase inhibitor, has shown to prolong median survival and time to radiologic progression and has now become standard treatment for advanced HCC [19]. Another option is Thalidomide, which is an oral systemic inhibitor of angiogenesis. Treatment with Thalidomide for advanced HCC has been in the focus of interest over the last years, but clinical data show only limited activity and are inconclusive [20-22]. So far, only one study describes the use of Thalidomide in HCC patients with intraatrial tumor extension. In the study of Chang et al., three patients with advanced HCC and inferior vena cava/right atrium tumor thrombi were assigned to Thalidomide. Two of the patients responded to Thalidomide with a survival of 15 months, whereas the third patient had symptomatic palliation [8].

\section{Conclusion}

Most cases of HCC develop on the basis of preexisting chronic liver disease with identifiable risk factors. Invasion of inferior vena cava represents a rare but catastrophic complication. We report the rare case of a patient with advanced HCC without any classical risk factors or underlying cirrhosis who presented with generalized oedema as a consequence of tumor invasion of the inferior vena cava with endovascular extension to the right atrium.

\section{Conflict of Interests}

The authors have no conflict of interests.

\section{Authors' Contribution}

C. Steinberg and I. Boulais wrote the paper. C. Steinberg, I. Boulais, and P. Chagnon designed the study. S. Boudreau performed pathologic analysis. F. Leveille performed positron emission tomography-CT. I. Boulais and M. Lamothe performed echocardiography.

\section{Acknowledgment}

Special thanks are due to Dr. Paul Poirier for careful reading of the paper.

\section{References}

[1] A. I. Gomaa, S. A. Khan, M. B. Toledano, I. Waked, and S. D. Taylor-Robinson, "Hepatocellular carcinoma: epidemiology, risk factors and pathogenesis," World Journal of Gastroenterology, vol. 14, no. 27, pp. 4300-4308, 2008.

[2] S. Caldwell and S. H. Park, "The epidemiology of hepatocellular cancer: from the perspectives of public health problem to tumor biology," Journal of Gastroenterology, vol. 44, supplement 19, pp. 96-101, 2009.
[3] K. D. Fairbanks and A. S. Tavill, "Liver disease in alpha 1antitrypsin deficiency: a review," American Journal of Gastroenterology, vol. 103, no. 8, pp. 2136-2141, 2008.

[4] M. C. Kew, "Hepatic iron overload and hepatocellular carcinoma," Cancer Letters, vol. 286, no. 1, pp. 38-43, 2009.

[5] T. Watanabe, K. Soga, H. Hirono et al., "Features of hepatocellular carcinoma in cases with autoimmune hepatitis and primary biliary cirrhosis," World Journal of Gastroenterology, vol. 15, no. 2, pp. 231-239, 2009.

[6] M. I. F. Shariff, I. J. Cox, A. I. Gomaa, S. A. Khan, W. Gedroyc, and S. D. Taylor-Robinson, "Hepatocellular carcinoma: current trends in worldwide epidemiology, risk factors, diagnosis and therapeutics," Expert Review of Gastroenterology and Hepatology, vol. 3, no. 4, pp. 353-367, 2009.

[7] C. J. Chen, M. W. Yu, and Y. F. Liaw, "Epidemiological characteristics and risk factors of hepatocellular carcinoma," Journal of Gastroenterology and Hepatology, vol. 12, supplement 9-10, pp. S294-S308, 1997.

[8] J. Y. Chang, W. S. Ka, T. Y. Chao, T. W. Liu, T. R. Chuang, and L. T. Chen, "Hepatocellular carcinoma with intra-atrial tumor thrombi: a report of three cases responsive to thalidomide treatment and literature review," Oncology, vol. 67, no. 3-4, pp. 320-326, 2004.

[9] A. D. Sung, S. Cheng, J. Moslehi, E. P. Scully, J. M. Prior, and J. Loscalzo, "Hepatocellular carcinoma with intracavitary cardiac involvement: a case report and review of the literature," American Journal of Cardiology, vol. 102, no. 5, pp. 643-645, 2008.

[10] H. A. Edmondson and P. E. Steiner, "Primary carcinoma of the liver: a study of 100 cases among 48,900," Cancer, vol. 7, no. 3, pp. 462-503, 1954.

[11] Y. Kato, N. Tanaka, and K. Kobayashi, "Growth of hepatocellular carcinoma into the right atrium. Report of five cases," Annals of Internal Medicine, vol. 99, no. 4, pp. 472-474, 1983.

[12] S. Ohwada, Y. Tanahashi, Y. Kawashima et al., "Surgery for tumor thrombi in the right atrium and inferior vena cava of patients with recurrent hepatocellular carcinoma," HepatoGastroenterology, vol. 41, no. 2, pp. 154-157, 1994.

[13] G. S. W. Chan, W. K. Ng, I. O. L. Ng, and P. Dickens, "Sudden death from massive pulmonary tumor embolism due to hepatocellular carcinoma," Forensic Science International, vol. 108, no. 3, pp. 215-221, 2000.

[14] J. Saïsse, J. Hardwigsen, P. Castellani, T. Caus, and Y. P. Le Treut, "Budd-Chiari syndrome secondary to intracardiac extension of hepatocellular carcinoma. Two cases treated by radical resection," Hepato-Gastroenterology, vol. 48, no. 39, pp. 836-839, 2001.

[15] T. P. Tsai and J. M. Yu, "Minimally invasive cardiac surgery for resection of right atrial hepatic tumor in an octogenarian," Chinese Medical Journal, vol. 65, no. 7, pp. 345-347, 2002.

[16] Y. Dazai, T. Katoh, I. Katoh, S. Sueda, and R. Yoshida, "Effectiveness of chemoembolization therapy for metastatic right atrial tumor thrombus associated with hepatocellular carcinoma," Chest, vol. 96, no. 2, pp. 434-436, 1989.

[17] Y. Kashima, M. Miyazaki, H. Ito et al., "Effective hepatic artery chemoembolization for advanced hepatocellular carcinoma with extensive tumour thrombus through the hepatic vein," Journal of Gastroenterology and Hepatology, vol. 14, no. 9, pp. 922-927, 1999.

[18] T. Yau, P. Chan, R. Epstein, and R. T. Poon, "Evolution of systemic therapy of advanced hepatocellular carcinoma," World Journal of Gastroenterology, vol. 14, no. 42, pp. 6437-6441, 2008. 
[19] J. M. Llovet, S. Ricci, V. Mazzaferro et al., "Sorafenib in advanced hepatocellular carcinoma," New England Journal of Medicine, vol. 359, no. 4, pp. 378-390, 2008.

[20] T. Yau, P. Chan, H. Wong et al., "Efficacy and tolerability of lowdose thalidomide as first-line systemic treatment of patients with advanced hepatocellular carcinoma," Oncology, vol. 72, supplement 1, pp. 67-71, 2007.

[21] M. Pinter, M. Wichlas, K. Schmid et al., "Thalidomide in advanced hepatocellular carcinoma as antiangiogenic treatment approach: a phase I/II trial," European Journal of Gastroenterology and Hepatology, vol. 20, no. 10, pp. 1012-1019, 2008.

[22] S. H. Han, S. H. Park, J. H. Kim et al., "Thalidomide for treating metastatic hepatocellular carcinoma: a pilot study," Korean Journal of Internal Medicine, vol. 21, no. 4, pp. 225-229, 2006. 


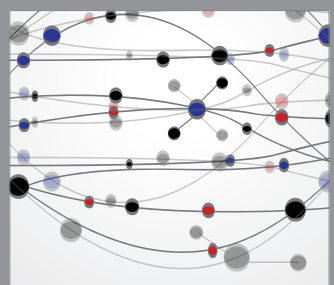

The Scientific World Journal
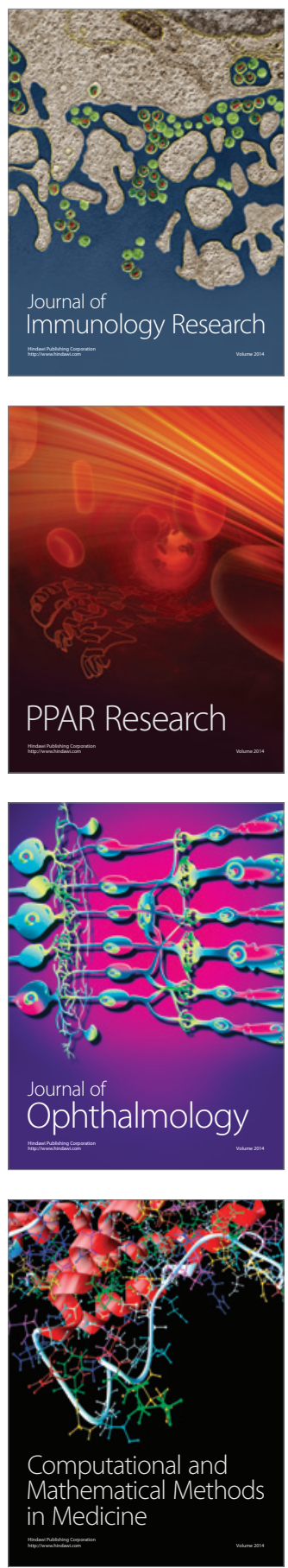

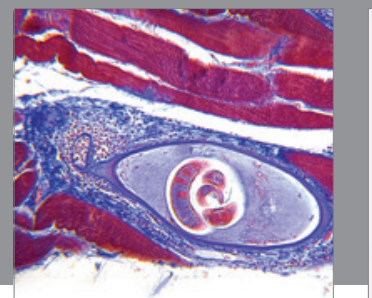

Gastroenterology

Research and Practice
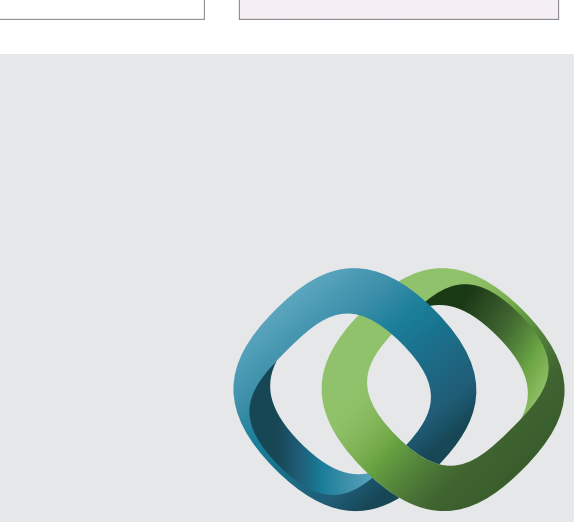

\section{Hindawi}

Submit your manuscripts at

http://www.hindawi.com
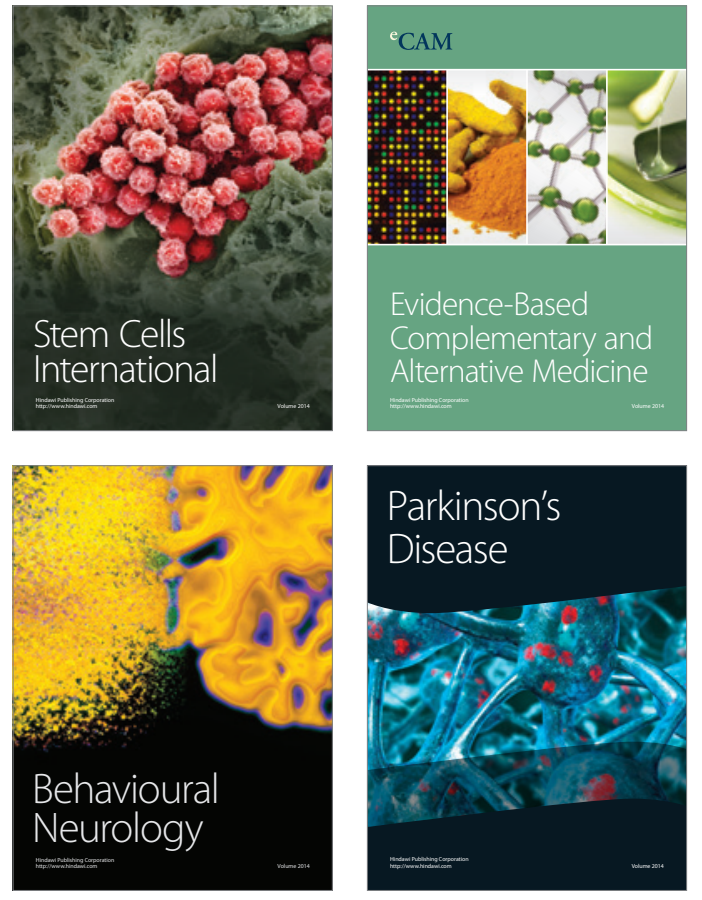
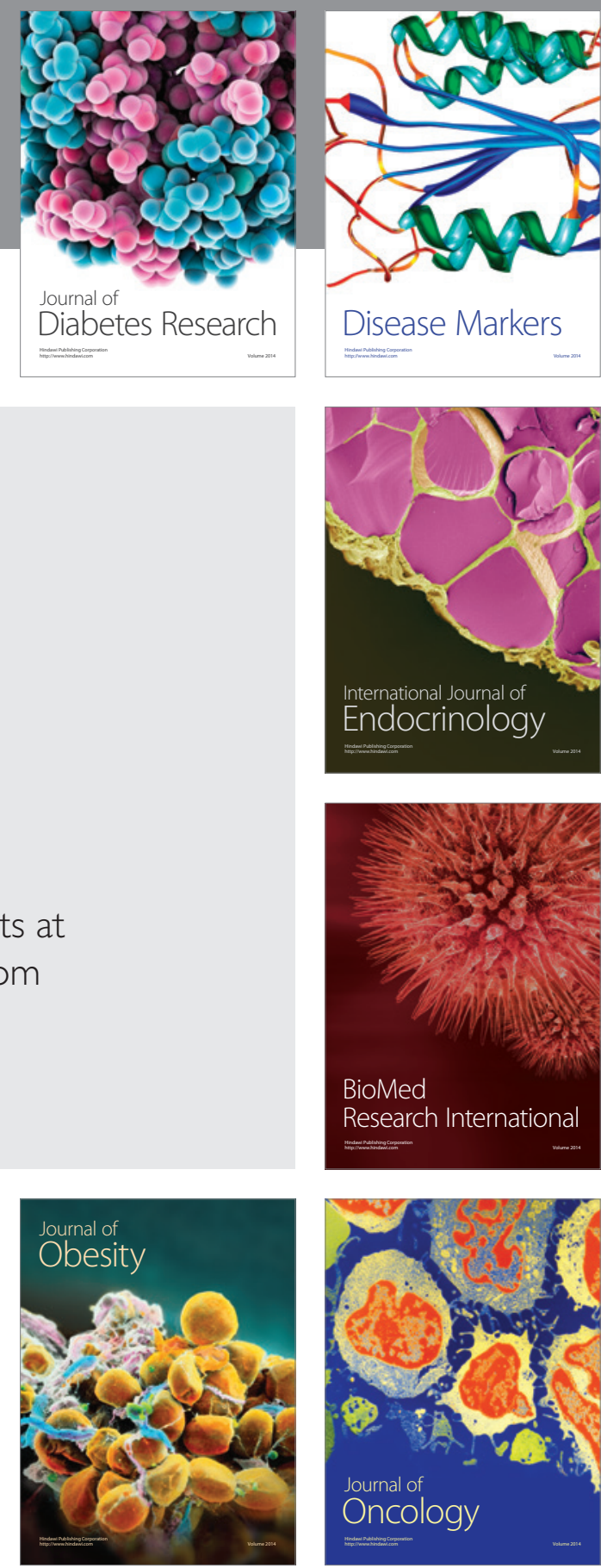

Disease Markers
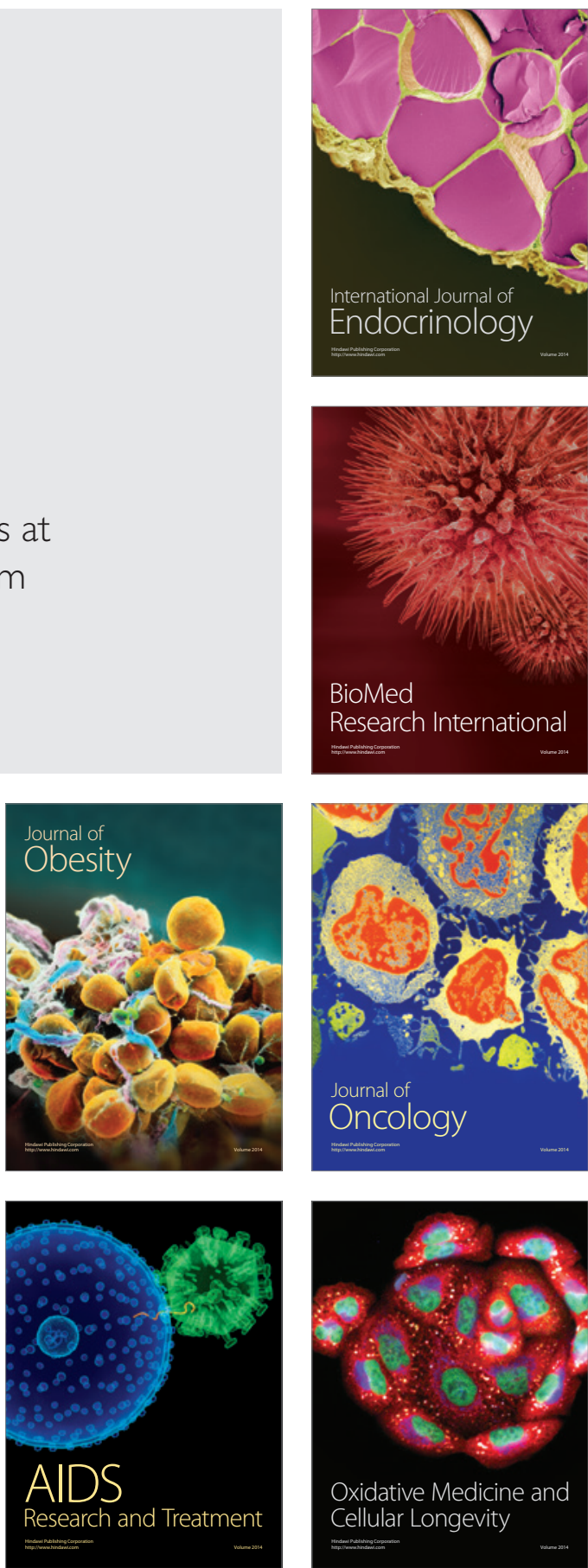